\title{
Venous thromboembolism in patients with adrenocortical carcinoma after surgery
}

\author{
Jülide Durmuşoğlu' ${ }^{1}$, Henri J L M Timmers ${ }^{1}$, Pepijn van Houten ${ }^{1}{ }^{1}$, Johan F Langenhuijsen ${ }^{2}$, Ad R M M Hermus ${ }^{1}$ and \\ Annenienke $\mathrm{C}$ van de Ven ${ }^{1}$
}

'Division of Endocrinology, Department of Medicine, Radboud University Nijmegen Medical Centre, Nijmegen, the Netherlands

2Department of Urology, Radboud University Nijmegen Medical Centre, Nijmegen, the Netherlands

\begin{abstract}
Background: Adrenocortical carcinoma is a rare malignancy with a poor prognosis. We hypothesized that patients with adrenocortical carcinoma are at high risk for venous thromboembolism, given the numerous risk factors such as malignancy, abdominal surgery, immobility and hormonal excess. The aim of this study was to determine retrospectively the incidence of venous thromboembolisms after surgical treatment in patients with adrenocortical carcinoma.

Materials and methods: A retrospective study was performed, collecting data from all patients diagnosed with adrenocortical carcinoma from 2003 to 2018 at the Radboud University Medical Centre, The Netherlands.

Results: In 34 patients, eight postoperative venous thromboembolisms, all pulmonary embolisms, were diagnosed in the first 6 months after adrenalectomy (23.5\%). In addition, one patient developed pulmonary embolism just prior to surgery and one patient 7 years after surgery. Five of the eight patients with postoperative venous thromboembolisms presented with symptomatic pulmonary embolism whereas the other three pulmonary embolisms were incidentally found on regular follow up CT scans. Seven of the eight venous thromboembolisms occurred within 10 weeks after surgery. Seven of the eight patients had advanced stage adrenocortical carcinoma and four patients already received low-molecular weight heparin during the development of the venous thromboembolism. There was one case of fatal pulmonary embolism in a patient with a cortisol producing tumor with pulmonary metastases, despite the use of a therapeutic dose thromboprophylaxis.

Conclusion: Patients with adrenocortical carcinoma are at high risk of developing postoperative venous thromboembolisms. Prolonged postoperative thromboprophylaxis could be considered in these patients.
\end{abstract}

\section{Introduction}

Adrenocortical carcinoma (ACC) is a rare and usually aggressive malignancy of the adrenal cortex. It has an annual incidence of approximately one case per million individuals $(1,2)$. The pillar of treatment for ACC is complete surgical resection (3). The 5-year survival of ACC is ranging from 16 to $45 \%(4,5,6)$, depending on the European Network for the Study of Adrenal Tumors staging (ENSAT) stage (7). Patients frequently present at an advanced stage and recurrence rates of ACC after resection are high $(6,8)$. ACC may be classified as functional (hormone-secreting) or nonfunctional. Functional adrenal tumors of the cortex can produce cortisol, androgens, https://ec.bioscientifica.com

https://doi.org/10.1530/EC-20-0299 (c) 2020 The authors Published by Bioscientifica Ltd

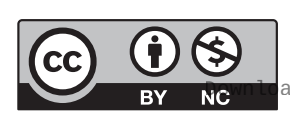

This work is licensed under a Creative Commons Attribution-NonCommercial 4.0 International License. ded from Bioscientifica.com at 04/26/2023 02:03:02PM
Endocrine Connections (2020) 9, 874-881 
estrogens and aldosterone. A functional ACC can cause hormone-specific symptoms and signs in patients (9). The most common clinical presentation of functional ACC is Cushing's syndrome $(9,10,11)$.

Venous thromboembolism (VTE) is a potential fatal complication (12). One might expect a high incidence of VTE in patients with ACC since malignancy, abdominal surgery and chemotherapy are associated with VTE $(13,14)$. In addition, hormonal excess of cortisol and androgens/estrogens are also associated with an increased risk of VTE $(15,16,17,18,19)$.

There are a few reports on the incidence of postoperative VTE in patients with ACC (20). One study has examined postoperative complications in ACC patients after adrenalectomy (21). The study reported a postoperative VTE incidence rate of $3 \%$ in the functional ACC group and $2 \%$ in the nonfunctional group. However, the study registered only the complications during the hospital stay. The incidence of VTE in ACC patients after adrenalectomy during a longer follow-up period is unknown.

The aim of this study was to determine the incidence of VTE in ACC patients after adrenalectomy.

\section{Methods}

A retrospective study using data from Radboud University Medical Centre in the Netherlands was performed.

Records of all patients who were diagnosed with ACC and who underwent primary tumor resection between January 2003 and January 2018 were examined. All included cases were followed from surgery until the date of the last follow-up visit or death. The exclusion criterion was an age below 18 years at the time of surgery.

Data were obtained regarding patient characteristics, hormonal excess, size of the tumor, laterality, presence of metastases, stage of disease, proliferation rate based on MIB-1 labeling, remission and recurrence after surgery. The diagnosis of ACC was based on the pathology report of the adrenal gland, primarily based on the Weiss criteria (3). Data on endocrine laboratory tests such as 24-h urinary cortisol excretion, the $1 \mathrm{mg}$ dexamethasone suppression test and plasma ACTH, DHEA-S, testosterone, estrogen and aldosterone levels were obtained in order to classify hormonal excess. Overt hypercortisolism was defined as an elevated 24-h urinary cortisol excretion in combination with an abnormal response to the $1 \mathrm{mg}$ dexamethasone suppression test. Subclinical hypercortisolism was defined as an abnormal response to the $1 \mathrm{mg}$ dexamethasone suppression test in combination with normal 24-h urine cortisol excretion. The patients were classified in low/intermediate-risk patients and advanced stage patients based on the ENSAT system (7) and on the Mib-1 labeling index (22). Patients with ENSAT stadium 1 and 2 (T1-2, N0, M0) and Mib-1 labeling index $\leq 10 \%$ were considered as low/intermediate-risk patients. Patients with ENSAT stadium 3 and 4 and/or Mib-1 labeling index > 10\% were considered as the high-risk patients. The highrisk patients and patients with metastatic disease were regarded as the advanced stage group. The definition of remission after surgery was the absence of metastatic disease on preoperative CT scan of chest and abdomen and complete resection during surgery (R0). Furthermore, data regarding treatment details of ACC were collected, including type of surgical approach, radiotherapy, chemotherapy and mitotane.

The primary outcome of our study was the incidence of venous thromboembolic events after adrenalectomy. We considered a VTE within 6 months after surgery as a postoperative VTE (23). VTE comprises pulmonary embolism and deep venous thrombosis. Patients were classified to have a deep venous thrombosis when diagnosis was confirmed by duplex ultrasound of the leg. Patients were considered to have a pulmonary embolism when this diagnosis was confirmed by spiral CT or autopsy. The presence of symptoms and risk factors (use of oral contraceptives, smoking and thrombophilia) was documented. For each patient, information on type, dose, and duration of thromboprophylaxis after surgery was documented. In addition, the incidence of bleeding complications during thromboprophylaxis use was registered.

Statistical analysis was performed using SPSS (IBM, version 22; SPSS, Inc). Incidence rates for VTE were calculated by dividing the observed number of VTEs within 6 months after the surgery by the total number of patients included. ACC patients were divided in two groups; patients with the development of postoperative VTE and patients without the development of postoperative VTE. Categorical data were compared with use of Fisher's exact test. Continuous variables were compared with the nonparametric Mann-Whitney $U$-test. $P$ values of less than 0.05 were considered to indicate statistical significance.

This study was approved by the ethical committee of our hospital (Commissie Mensgebonden Onderzoek). Consent has been obtained from each patient (if alive) after full explanation of the purpose and nature of all procedures used.

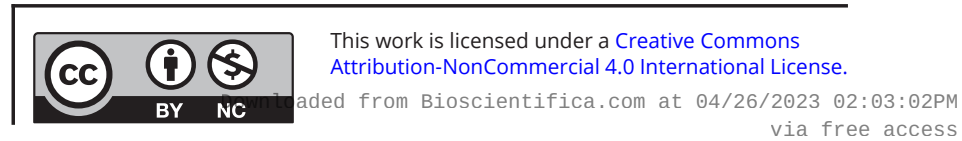




\section{Results}

\section{Patients}

From January 2003 until April 2018, a total of 40 patients were diagnosed with ACC. Of these 40 patients, 5 were excluded because they did not undergo surgery and one was excluded because of the fact that the patient was younger than 18 years. Of these six excluded patients, one developed a VTE during the disease period of ACC. In total, 34 patients were included in the study. The median duration of follow-up was 16.5 months with a range from 1 to 105 months.

\section{Characteristics}

The main demographic, clinical and treatment characteristics are provided in Table 1 . The majority of the patients were female (23/34), and the median age at time of surgery was 60 years (range $24-80$ years). Of all included patients, 27 underwent laparotomy and 7 transperitoneal

Table 1 Patient characteristics.

\begin{tabular}{l} 
Characteristics \\
\hline Sex, female, $n$ \\
Age, year, median (range) \\
Men \\
Women \\
BMI, median (range) \\
Smoking, yes, $n$ \\
Oral contraceptive pill, yes, $n$ \\
Tumor size, cm, median (range) \\
Laterality, $n$ \\
Left \\
Right \\
Mib-1 labeling index, median \% (range) \\
Vascular invasion, yes, $n$ \\
Tumor thrombus before surgery, $n$ \\
Advanced stage ACC based on ENSAT, $n$ \\
Metastasis before surgery, yes, $n$ \\
Functional tumor, yes, $n$ \\
Type of tumor, $n$ \\
Nonfunctional \\
Overt hypercortisolism \\
Subclinical hypercortisolism \\
Cortisol- and androgen production \\
Androgen production \\
Aldosterone production \\
Cortisol and estrogen production \\
Unknown \\
Adrenal surgeries \\
Laparotomy, $n$ \\
Laparoscopy, $n$ \\
Remission after surgery, $n$ \\
Radiotherapy after surgery, $n$ \\
Mitotane after surgery, $n$ \\
Recurrence after remission, $n$ \\
Recurrence after surgery in months, \\
median (range) \\
Duration thromboprophylaxis after \\
surgery in days, median (range) \\
Bleeding during thromboprophylaxis, $n$ \\
Follow-up in months, median (range) \\
Deaths, $n$ \\
ü Disease-specific, $n$ \\
Other, $n$ \\
\hline
\end{tabular}

\begin{tabular}{c}
\hline $\begin{array}{c}\text { All ACC patients } \\
(n=34)\end{array}$ \\
\hline 23 \\
$60(24-80)$ \\
51 \\
61.5 \\
$24.5(18.9-42.9)$ \\
8 \\
1 \\
$13(3-30)$
\end{tabular}

19
15
$10(1-50)$
25
6
18
10
23

\begin{tabular}{c}
$\begin{array}{c}\text { No postoperative VTE } \\
(n=26)\end{array}$ \\
\hline 17 \\
$58(24-80)$ \\
51 \\
62.5 \\
23.8 \\
7 \\
0 \\
$13(3-30)$
\end{tabular}

$1 \quad 0$

27

7

23

0

11

9

$3(0-47)$

5 (2-95)

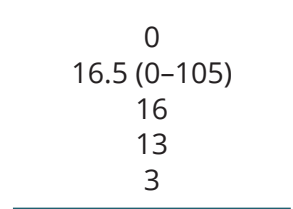

15

11

10

18

3

11

6

17

$5 \quad 2$

$\begin{array}{ll}5 & 2 \\ 6 & 2\end{array}$

4

43

1 0

1

4

21

$$
5
$$$$
19
$$$$
0
$$$$
7
$$$$
7
$$$$
5.5(0-47)
$$

8 (4-95)

0.171

0.403

0.126

0.046

0.195

0.623

0.642

0.300

0.644

aCategorical variables: Fisher's exact test. Continuous variables: Mann-Whitney U-test. ACC, adrenocortical carcinoma; BMI, body mass index; VTE, venous thromboembolic events.

https://ec.bioscientifica.com https://doi.org/10.1530/EC-20-0299 (c) 2020 The authors Published by Bioscientifica Ltd

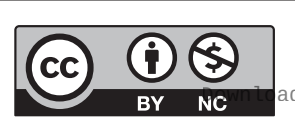

This work is licensed under a Creative Commons Attribution-NonCommercial 4.0 International License. ded from Bioscientifica.com at 04/26/2023 02:03:02PM 
laparoscopic surgery. The average tumor size was $13.6 \mathrm{~cm}$ (range 3-30 cm). Of the 34 ACCs, 23 exhibited hormonal excess. The three most common types of hormonal overproduction were overt hypercortisolism (8/34), subclinical hypercortisolism (5/34), and a combination of overt hypercortisolism and hyperandrogenism (7/34). In total, 10 patients were diagnosed with metastases before surgery. The two most common metastatic locations were liver (6/34) and lung (5/34). Of all 34 patients, 23 had a complete resection of the tumor. Of these 23 patients 9 had recurrence of disease after a median time of 3 months (range 0-47 months).

\section{Thromboprophylaxis}

Information on the use of thromboprophylaxis after surgery was available for 25 patients. Low-molecular weight heparin (LMWH) nadroparin 2850 U/day $(=0.3$ $\mathrm{mL}$ ) was used as postoperative thromboprophylaxis in all 25 patients, according to the local protocol. The median duration of thromboprophylaxis after surgery was 5 days (range 2-95 days). Of these patients, 19 stopped using thromboprophylaxis after mobilization and hospital discharge. No bleeding complications occurred during the use of postoperative thromboprophylaxis. However, one patient developed major psoas bleeding during the use of a therapeutic dose of nadroparin after diagnosis of pulmonary embolism.

\section{Outcome}

Postoperative VTE occurred in 8 of the 34 patients. More details of the eight patients with postoperative VTE are shown in Table 2. All eight postoperative VTEs were pulmonary embolisms. None of the eight patients with pulmonary embolism had clinical signs of deep venous thrombosis of the leg. However, duplex ultrasound to rule out deep venous thrombosis of the legs was not performed routinely. Five patients presented with symptomatic pulmonary embolism whereas three pulmonary embolisms were incidentally found on regular follow up CT scans. All events occurred between 4 and 146 days after surgery, with a median of 40 days. Seven of the eight pulmonary embolisms occurred within 10 weeks postoperatively. None of the patients developed VTE during hospital stay. However, one patient developed VTE one day after discharge, 4 days after surgery. Of the eight patients, two patients received prophylactic LMWH during the development of the VTE and two other patients received therapeutic LMWH.
Seven of the eight patients with postoperative pulmonary embolism were patients with advanced stage ACC. Of the eight patients with postoperative VTE, one patient was smoking and one patient was using oral contraceptive pill. None of the patients had a history of VTE or thrombophilia. One patient with a cortisol producing ACC with lung metastases died 1 month after the diagnosis pulmonary embolism because of progressive pulmonary embolisms (confirmed by autopsy) despite the use of therapeutic nadroparin. Of the 34 ACC patients, one patient developed pulmonary embolism one day before the adrenal surgery and one patient 7 years after the adrenal surgery. These events were not considered as a postoperative VTE.

\section{Discussion}

This study shows a high incidence rate of VTE of $23.5 \%$ within 6 months after adrenal surgery in patients with ACC. All of the VTEs that occurred in our cohort were pulmonary embolisms. ACC patients are at high risk of developing postoperative pulmonary embolism.

The postoperative VTE incidence rate that we found was much higher compared to the incidence rate of VTE in a previous study by Parikh et al. which found a rate of $2-3 \%$ of postoperative VTEs in patients with ACC (21). The major difference between the studies is the fact that the previous study focused on the occurrence of postoperative VTE only during the hospital stay with a mean length of hospital stay of 9 days. In addition, as mentioned by the authors of the study, data were collected from an administrative database that depended on diagnostic codes that can lead to coding errors. For this reason, it is possible that some cases of VTE may have been missed. By contrast, a study by Bergqvist et al. (24) demonstrated a high VTE rate of $12 \%$ in patients with abdominal and pelvic cancer receiving LMWH for 1 week after surgery. A meta-analysis by Li et al. demonstrated an overall incidence of VTE after oncologic surgery for a broad number of different cancers of $2.3 \%$ (25). The follow-up length of included studies varied between 7 and 90 days postoperatively. The incidence of VTE in our cohort is much higher. We hypothesize that this difference is caused by aforementioned risk factors of VTE which were present in the patients in our cohort: malignancy, abdominal surgery and hormonal excesses. To our knowledge, the incidence rate of VTE during a longer postoperative follow-up period for ACC patients was not investigated in other studies before. 


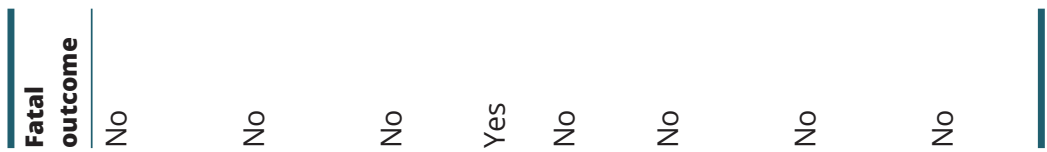
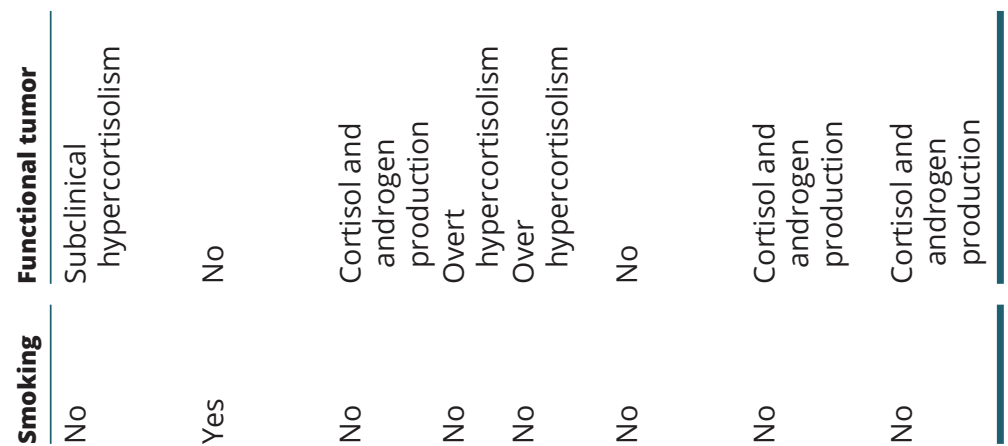

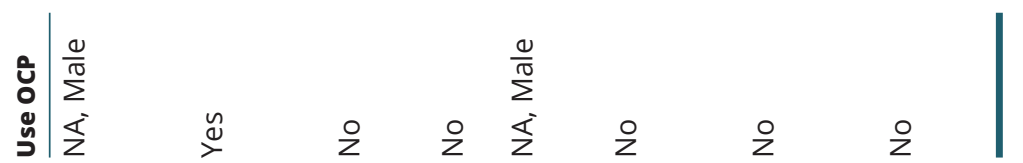

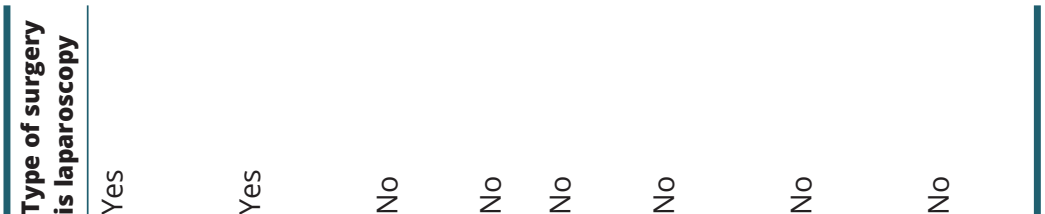

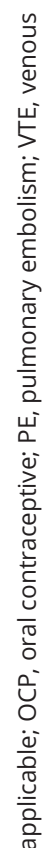
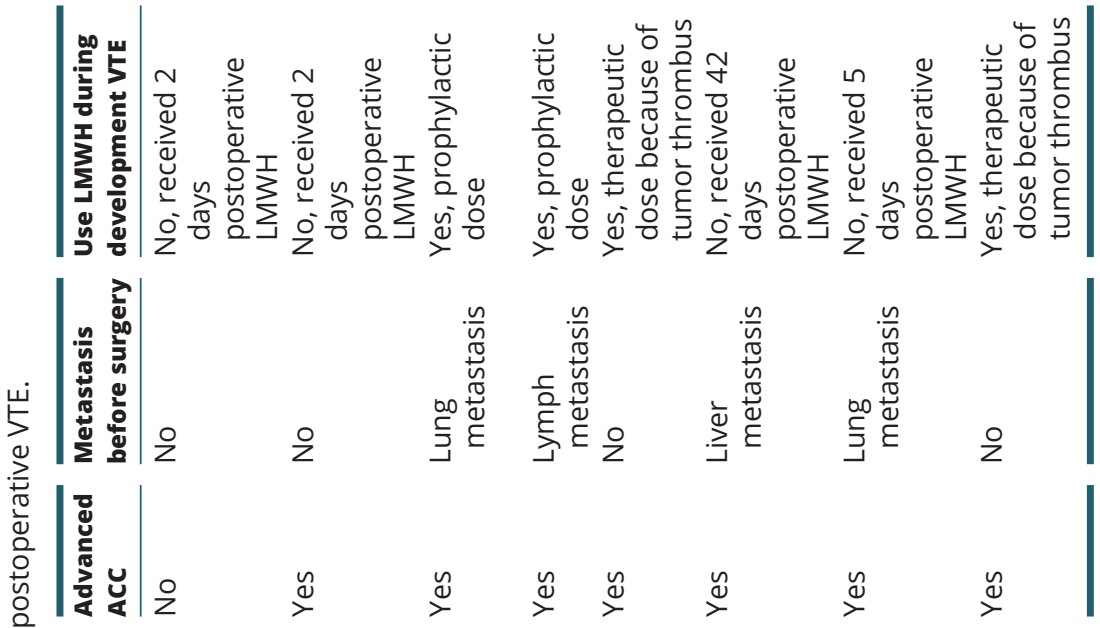

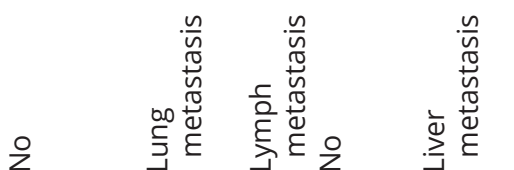

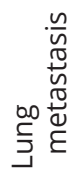

$\stackrel{\Perp}{\rightleftharpoons}$

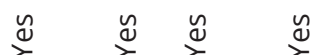

$\stackrel{y}{\rightleftharpoons}$

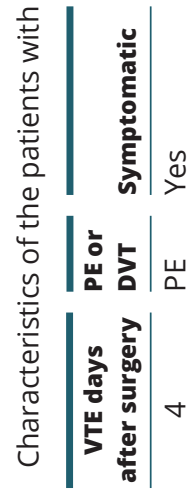

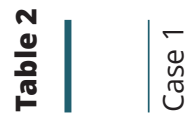

尊

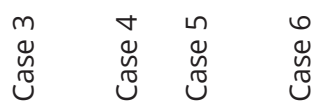

$\stackrel{\sim}{\cup}$

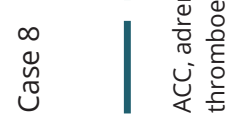


Although our cohort was relatively small and one should be careful interpreting subgroup analysis, we observed a striking higher incidence of VTE in patients with an advanced stage of the disease according to the ENSAT classification. Other variables were not associated with an increased risk of postoperative VTE. Seven of the 8 patients with postoperative pulmonary embolism were patients with advanced stage ACC. It has been previously described that biologically aggressive tumors correlate with a higher incidence of VTE (26).

As mentioned in the introduction, previous studies have shown that hormonal overproduction is associated with VTE, even after resection of the hormone-producing tumor $(15,16,17,18,19)$. For example, VTE has been reported in $1.9-2.5 \%$ of patients with glucocorticoid excess due to Cushing's syndrome, with postoperative incidence varying between 0 and 5.6\% (18). Against our expectations, the incidence of postoperative VTE in patients with functional ACC was not higher compared to patients with nonfunctional ACC in our study. The results of the study by Parikh et al. regarding postoperative complications during hospital stay found a small difference between functional and nonfunctional tumors which was not significant (21). Our study population might be too small to demonstrate small differences between subgroups. A further study with a larger study population is needed to evaluate the effect of hormone excess on the development of postoperative VTE in patients with ACC.

The patients in our study received thromboprophylaxis for various durations. Most of them received thromboprophylaxis only during the post-operative hospital stay. Given the rarity of ACC, there are no specific guidelines on the duration of postoperative thromboprophylaxis. One of the most authoritative studies on the duration of postoperative thromboprophylaxis in patients with abdominal carcinomas is the study by Bergqvist et al. (24). Their randomized controlled trial demonstrated a VTE rate of $12 \%$ in patients with abdominal and pelvic cancer receiving LMWH for 1 week after surgery and a VTE rate of $4.8 \%$ in patients receiving LMWH for 4 weeks after surgery (24). Therefore, the American Society of Clinical Oncology (ASCO) guideline of 2014 recommends 4 weeks of thromboprophylaxis after abdominal and pelvic cancer surgery $(27,28)$. Importantly, the observed incidence rate of $12 \%$ with 1 week postoperative prophylaxis in the study of Bergqvist et al. (24) is lower than the incidence rate in our study. There might be a different optimal regimen of postoperative thromboprophylaxis in patients with ACC. In our study, the majority of the VTEs occurred within 10 weeks after surgery. Therefore, for patients with ACC, it might be beneficial to prescribe postoperative thromboprophylaxis during a longer period of 3 months instead of the recommended period of 4 weeks after surgery.

In our study population, one patient developed a major psoas bleeding while using therapeutic dosage of LMWH because of pulmonary embolism. Bleeding risks are high in cancer patients with therapeutic dosages of anticoagulants (29). None of the patients in our study developed major bleeding complications during prophylactic dosage of LWMH. However, some patients even developed VTE despite the use of therapeutic and prophylactic dosages of LWMH. Our observations confirm the complexity of balancing the risks of bleeding vs thrombosis in this patient category.

A relatively large proportion of patients in our cohort underwent surgery despite presenting with metastasized disease at diagnosis (10/34). Although surgery is not standard treatment of choice in patients with metastasized ACC, it was performed in these patients to reduce symptoms caused by hormonal excess or to reduce or prevent symptoms caused by large tumor mass, as recommended by the available guideline (30).

One limitation of our study is its retrospective nature. For example, the duration of postoperative thromboprophylaxis was not findable for all patients. In addition, we were not able to determine the performance status at diagnosis. Another important limitation is the small sample size of our study, due to the rarity of the disease. Notwithstanding the relatively limited sample, this work offers important insights regarding the incidence of postoperative venous thromboembolism in ACC patients. In the future, a prospective multicenter study is needed to confirm the high risk of postoperative VTE in patients with ACC and to determine the effect of thromboprophylaxis in these patients.

In conclusion, patients with ACC, especially advanced stage ACC, are at high risk of developing a VTE after adrenal surgery. Prolonged postoperative thromboprophylaxis of 3 months could be considered in patients with ACC. Further research should be undertaken to investigate the optimal duration and dosage of thromboprophylaxis for ACC patients, also taking the risk of bleeding complications into account.

Declaration of interest

The authors declare that there is no conflict of interest that could be perceived as prejudicing the impartiality of the research reported.

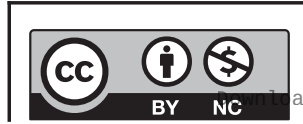

This work is licensed under a Creative Commons Attribution-NonCommercial 4.0 International License. ded from Bioscientifica.com at 04/26/2023 02:03:02PM 


\section{Funding}

This research did not receive any specific grant from any funding agency in the public, commercial or not-for-profit sector.

\section{Acknowledgements}

The authors thank all of the patients who participated in this study.

\section{References}

1 Kerkhofs TM, Verhoeven RH, Van der Zwan JM, Dieleman J, Kerstens MN, Links TP, Van de Poll-Franse LV \& Haak HR Adrenocortical carcinoma: a population-based study on incidence and survival in the Netherlands since 1993. European Journal of Cancer 201349 2579-2586. (https://doi.org/10.1016/j. ejca.2013.02.034)

2 Kebebew E, Reiff E, Duh QY, Clark OH \& McMillan A. Extent of disease at presentation and outcome for adrenocortical carcinoma: have we made progress? World Journal of Surgery 200630 872-878. (https://doi.org/10.1007/s00268-005-0329-x)

3 Fassnacht M, Kroiss M \& Allolio B. Update in adrenocortical carcinoma. Journal of Clinical Endocrinology and Metabolism 201398 4551-4564. (https://doi.org/10.1210/jc.2013-3020)

4 Tran TB, Postlewait LM, Maithel SK, Prescott JD, Wang TS, Glenn J, Phay JE, Keplinger K, Fields RC, Jin LX, et al. Actual 10-year survivors following resection of adrenocortical carcinoma. Journal of Surgical Oncology 2016114 971-976. (https://doi.org/10.1002/ jso.24439)

5 Vanbrugghe C, Lowery AJ, Golffier C, Taieb D \& Sebag F. Adrenocortical carcinoma surgery-surgical extent and approach. Langenbeck's Archives of Surgery 2016401 991-997. (https://doi. org/10.1007/s00423-016-1462-8)

6 Bilimoria KY, Shen WT, Elaraj D, Bentrem DJ, Winchester DJ, Kebebew E \& Sturgeon C. Adrenocortical carcinoma in the United States: treatment utilization and prognostic factors. Cancer $2008 \mathbf{1 1 3}$ 3130-3136. (https://doi.org/10.1002/cncr.23886)

7 Libé R, Borget I, Ronchi CL, Zaggia B, Kroiss M, Kerkhofs T, Bertherat J, Volante M, Quinkler M, Chabre O, et al. Prognostic factors in stage III-IV adrenocortical carcinomas (ACC): an European Network for the Study of Adrenal Tumor (ENSAT) study. Annals of Oncology 201526 2119-2125. (https://doi.org/10.1093/annonc/ mdv329)

8 Amini N, Margonis GA, Kim Y, Tran TB, Postlewait LM, Maithel SK, Wang TS, Evans DB, Hatzaras I, Shenoy R, et al. Curative resection of adrenocortical carcinoma: rates and patterns of postoperative recurrence. Annals of Surgical Oncology 201623 126-133. (https://doi. org/10.1245/s10434-015-4810-y)

9 Else T, Kim AC, Sabolch A, Raymond VM, Kandathil A, Caoili EM, Jolly S, Miller BS, Giordano TJ \& Hammer GD. Adrenocortical carcinoma. Endocrine Reviews 201435 282-326. (https://doi. org/10.1210/er.2013-1029)

$10 \mathrm{Ng}$ L \& Libertino JM. Adrenocortical carcinoma: diagnosis, evaluation and treatment. Journal of Urology 2003169 5-11. (https:// doi.org/10.1097/01.ju.0000030148.59051.35)

11 Gaujoux S, Weinandt M, Bonnet S, Reslinger V, Bertherat J \& Dousset B. Surgical treatment of adrenal carcinoma. Journal of Visceral Surgery 2017 154 335-343. (https://doi.org/10.1016/j.jviscsurg.2017.06.010)

12 Agnelli G, Bolis G, Capussotti L, Scarpa RM, Tonelli F, Bonizzoni E, Moia M, Parazzini F, Rossi R, Sonaglia F, et al. A clinical outcomebased prospective study on venous thromboembolism after cancer surgery: the @RISTOS project. Annals of Surgery 2006243 89-95. (https://doi.org/10.1097/01.sla.0000193959.44677.48)
13 Donati MB \& Lorenzet R. Thrombosis and cancer: 40 years of research. Thrombosis Research 2012129 348-352. (https://doi. org/10.1016/j.thromres.2011.12.022)

14 Heit JA, Silverstein MD, Mohr DN, Petterson TM, O'Fallon WM \& Melton III LJ. Risk factors for deep vein thrombosis and pulmonary embolism: a population-based case-control study. Archives of Internal Medicine 2000160 809-815. (https://doi.org/10.1001/ archinte.160.6.809)

15 Martinez C, Suissa S, Rietbrock S, Katholing A, Freedman B, Cohen AT \& Handelsman DJ. Testosterone treatment and risk of venous thromboembolism: population based case-control study. BMJ 2016355 i5968. (https://doi.org/10.1136/bmj.i5968)

16 Mullard A \& Innes H. Venous thromboembolism in malignancy. Clinical Medicine 201414 532-534. (https://doi.org/10.7861/ clinmedicine.14-5-532)

17 Timp JF, Braekkan SK, Versteeg HH \& Cannegieter SC. Epidemiology of cancer-associated venous thrombosis. Blood 2013122 1712-1723. (https://doi.org/10.1182/blood-2013-04-460121)

18 Van Zaane B, Nur E, Squizzato A, Dekkers OM, Twickler MT, Fliers E, Gerdes VE, Buller HR \& Brandjes DP. Hypercoagulable state in Cushing's syndrome: a systematic review. Journal of Clinical Endocrinology and Metabolism 200994 2743-2750. (https://doi. org/10.1210/jc.2009-0290)

19 Stuijver DJF, Van Zaane B, Feelders RA, Debeij J, Cannegieter SC, Hermus AR, Van den Berg G, Pereira AM, De Herder WW, Wagenmakers MAEM, et al. Incidence of venous thromboembolism in patients with Cushing's syndrome: a multicenter cohort study. Journal of Clinical Endocrinology and Metabolism 201196 3525-3532. (https://doi.org/10.1210/jc.2011-1661)

20 van der Pas R, Leebeek FW, Hofland LJ, De Heder WW \& Feelders RA. Hypercoagulability in Cushing's syndrome: prevalence, pathogenesis and treatment. Clinical Endocrinology $2013 \mathbf{7 8}$ 481-488. (https://doi. org/10.1111/cen.12094)

21 Parikh PP, Rubio GA, Farra JC \& Lew JI. Nationwide analysis of adrenocortical carcinoma reveals higher perioperative morbidity in functional tumors. American Journal of Surgery 2018216 293-298. (https://doi.org/10.1016/j.amjsurg.2017.08.018)

22 Beuschlein F, Weigel J, Saeger W, Kroiss M, Wild V, Daffara F, Libé R, Ardito A, Al Ghuzlan A, Quinkler M, et al. Major prognostic role of Ki67 in localized adrenocortical carcinoma after complete resection. Journal of Clinical Endocrinology and Metabolism 2015100 841-849. (https://doi.org/10.1210/jc.2014-3182)

23 Huerta C, Johansson S, Wallander MA \& Garcia Rodriguez LA. Risk factors and short-term mortality of venous thromboembolism diagnosed in the primary care setting in the United Kingdom. Archives of Internal Medicine 2007167 935-943. (https://doi. org/10.1001/archinte.167.9.935)

24 Bergqvist D, Agnelli G, Cohen AT, Eldor A, Nilsson PE, Le MoigneAmrani A, Dietrich-Neto F \& ENOXACAN II Investigators. Duration of prophylaxis against venous thromboembolism with enoxaparin after surgery for cancer. New England Journal of Medicine 2002346 975-980. (https://doi.org/10.1056/NEJMoa012385)

$25 \mathrm{Li} \mathrm{M}$, Guo Q \& Hu W. Incidence, risk factors, and outcomes of venous thromboembolism after oncologic surgery: a systematic review and meta-analysis. Thrombosis Research 2019173 48-56. (https://doi.org/10.1016/j.thromres.2018.11.012)

26 Wun T \& White RH. Epidemiology of cancer-related venous thromboembolism. Best Practice and Research: Clinical Haematology 200922 9-23. (https://doi.org/10.1016/j.beha.2008.12.001)

27 Lyman GH, Khorana AA, Falanga A, Clarke-Pearson D, Flowers C, Jahanzeg M, Kakkar A, Kuderer NM, Levine MN, Liebman H, et al. American Society of Clinical Oncology guideline: recommendations for venous thromboembolism prophylaxis and treatment in patients with cancer. Journal of Clinical Oncology 200725 5490-5505. (https:// doi.org/10.1200/JCO.2007.14.1283) https://ec.bioscientifica.com https://doi.org/10.1530/EC-20-0299 (c) 2020 The authors Published by Bioscientifica Ltd

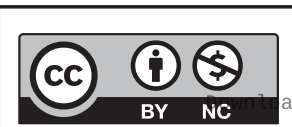

This work is licensed under a Creative Commons Attribution-NonCommercial 4.0 International License. ded from Bioscientifica.com at 04/26/2023 02:03:02PM 
28 Lyman GH, Bohlke K, Khorana AA, Kuderer NM, Lee AY, Arcelus JI, Balaban EP, Clarke JM, Flowers CR, Francis CW, et al. Venous thromboembolism prophylaxis and treatment in patients with cancer: American Society of Clinical Oncology clinical practice guideline update 2014. Journal of Clinical Oncology 201533 654-656. (https://doi.org/10.1200/JCO.2014.59.7351)

29 Prandoni P, Lensing AW, Piccioli A, Bernardi E, Simioni P, Girolami B, Marchiori A, Sabbion P, Prins MH, Noventa F, et al. Recurrent venous thromboembolism and bleeding complications during anticoagulant treatment in patients with cancer and venous thrombosis. Blood 2002100 3484-3488. (https://doi.org/10.1182/blood-2002-01-0108)

30 Berruti A, Baudin E, Gelderblom H, Haak HR, Porpiglia F, Fassnacht M, Pentheroudakis G \& ESMO Guidelines Working Group. Adrenal cancer: ESMO Clinical Practice Guidelines for diagnosis, treatment and follow-up. Annals of Oncology 201223 (Supplement 7) vii131-vii138. (https://doi.org/10.1093/annonc/mds231)

Received in final form 7 August 2020

Accepted 12 August 2020

Accepted Manuscript published online 12 August 2020
This work is licensed under a Creative Commons Attribution-NonCommercial 4.0 International License. 